\title{
Unchain my heart: the scientific foundations of cardiac repair
}

\author{
Stefanie Dimmeler, ${ }^{1}$ Andreas M. Zeiher, ${ }^{1}$ and Michael D. Schneider ${ }^{2}$
}

\author{
1Department of Molecular Cardiology, Department of Internal Medicine IV, University of Frankfurt, Frankfurt am Main, Germany. \\ ${ }^{2}$ Center for Cardiovascular Development, Departments of Medicine, Molecular \& Cellular Biology, and Molecular Physiology \& Biophysics, \\ Baylor College of Medicine, Houston, Texas, USA.
}

\begin{abstract}
In humans, the biological limitations to cardiac regenerative growth create both a clinical imperative - to offset cell death in acute ischemic injury and chronic heart failure - and a clinical opportunity; that is, for using cells, genes, and proteins to rescue cardiac muscle cell number or in other ways promote more efficacious cardiac repair. Recent experimental studies and early-phase clinical trials lend credence to the visionary goal of enhancing cardiac repair as an achievable therapeutic target.
\end{abstract}

Heart failure - a severe deficiency in ventricular pump function - arises through a finite number of terminal effector mechanisms, regardless of the cause. These include: defects intrinsic to cardiac muscle cells' contractility due to altered expression or operation of calcium-cycling proteins, components of the sarcomere, and enzymes for cardiac energy production; defects extrinsic to cardiac muscle cells, such as interstitial fibrosis, affecting organ-level compliance; and myocyte loss, unmatched by myocyte replacement. Cardiac regeneration is robust for certain organisms such as the newt and zebrafish, in which total replacement can transpire even for an amputated limb, fin, or tail, via production of an undifferentiated cell mass called the blastema (1). Such a degree of restorative growth might also be dependent on the retention of proliferative potential in a subset of adult cardiomyocytes (2) and is impossible in mammals under normal, unassisted biological circumstances. Several complementary strategies can be foreseen as potentially aiding this process: overriding cell-cycle checkpoints that constrain the reactive proliferation of ventricular myocytes (3); supplementing the cytoprotective mechanisms that occur naturally, or inhibiting pro-death pathways $(4,5)$; supplementing the angiogenic mechanisms that occur naturally using defined growth factors or vessel-forming cells $(6,7)$; or providing exogenous cells as a surrogate or precursor for cardiac muscle itself (8-10).

Among these conceptual possibilities, cell implantation in various forms has been the first strategy to be translated from bench to bedside. The possibility of tissue repair by autologous adult progenitor cells - suggested by the auspicious findings in experimental studies of various cell sources - immediately captured the attention of clinicians confronted with the disabling, life-threatening circumstance of patients who suffer from heart failure in acute or chronic ischemic heart disease. The promise of cellular cardiomyogenesis and neovascularization, individually or in tandem, offered altogether novel opportunities for treatment, tailored to the underlying pathobiology.

Nonstandard abbreviations used: BMP, bone morphogenetic protein; EGFP, enhanced green fluorescent protein; EPC, endothelial progenitor cell; HMGB1, high mobility group box protein 1; MAPC, multipotential adult progenitor cell; MHC, myosin heavy chain; MSC, mesenchymal stem cell; SDF-1, stromal cell-derived factor-1; SP, side population; TERT, telomerase reverse transcriptase.

Conflict of interest: The authors have declared that no conflict of interest exists.

Citation for this article: J. Clin. Invest. 115:572-583 (2005)

doi:10.1172/JCI200524283
Within just the past 3 years, more than a half-dozen early clinical studies have been published, ranging from case reports to formal trials, deploying a range of differing cell-based therapies with the shared objective of improving cardiac repair (11-16). Clinical follow-up for as long as a year is now available for some patients $(17,18)$. Despite their different strategies and cells, and lack of double-blinded controls, these small initial human trials in general point to a functional improvement; yet key questions remain open. Understanding better just why and how grafting works will be essential, alongside needed empirical trials, to engineer the soundest future for regenerative therapy in human heart disease.

\section{The inauguration of human cardiac repair}

Ventricular dysfunction is the sine qua non of heart failure. Conventional palliative medical management does not correct, or attempt to correct, underlying defects in cardiac muscle cell number. Moreover, while indispensable to current treatment of end-stage heart failure, more aggressive interventions such as cardiac transplantation and the use of mechanical LV assist devices (either as a bridge to transplantation or as "destination" therapy) are thwarted by comorbidity or finite effectiveness, inciting the search for more advanced methods $(19,20)$. This need for causally directed treatment - to complement mere support of the remaining healthy myocardium - has prompted the translation of a decade's experimental studies into clinical pilot trials studying cell-based myocardial regeneration and repair.

\section{Cell types}

Currently, a variety of adult progenitor cells are undergoing clinical evaluation - all autologous, so that tissue rejection is obviated (Figure 1). The first clinically relevant cells to be proposed as a surrogate for cardiomyocytes were skeletal muscle myoblasts - undifferentiated proliferation-competent cells that serve as precursors to skeletal muscle (21-23). For clinical use, autologous human myoblasts are isolated from skeletal muscle biopsies, propagated and expanded ex vivo for a few days or weeks, then injected directly into the ventricular wall $(11,24,25)$.

Bone marrow is, at present, the most frequent source of cells used for clinical cardiac repair $(12-14,16)$. Bone marrow contains a complex assortment of progenitor cells, including HSCs; socalled side population (SP) cells, defined by their ability to expel a Hoechst dye, which account for most if not all long-term selfrenewal $(26,27)$ and reconstitute the full panoply of hematopoietic 
A

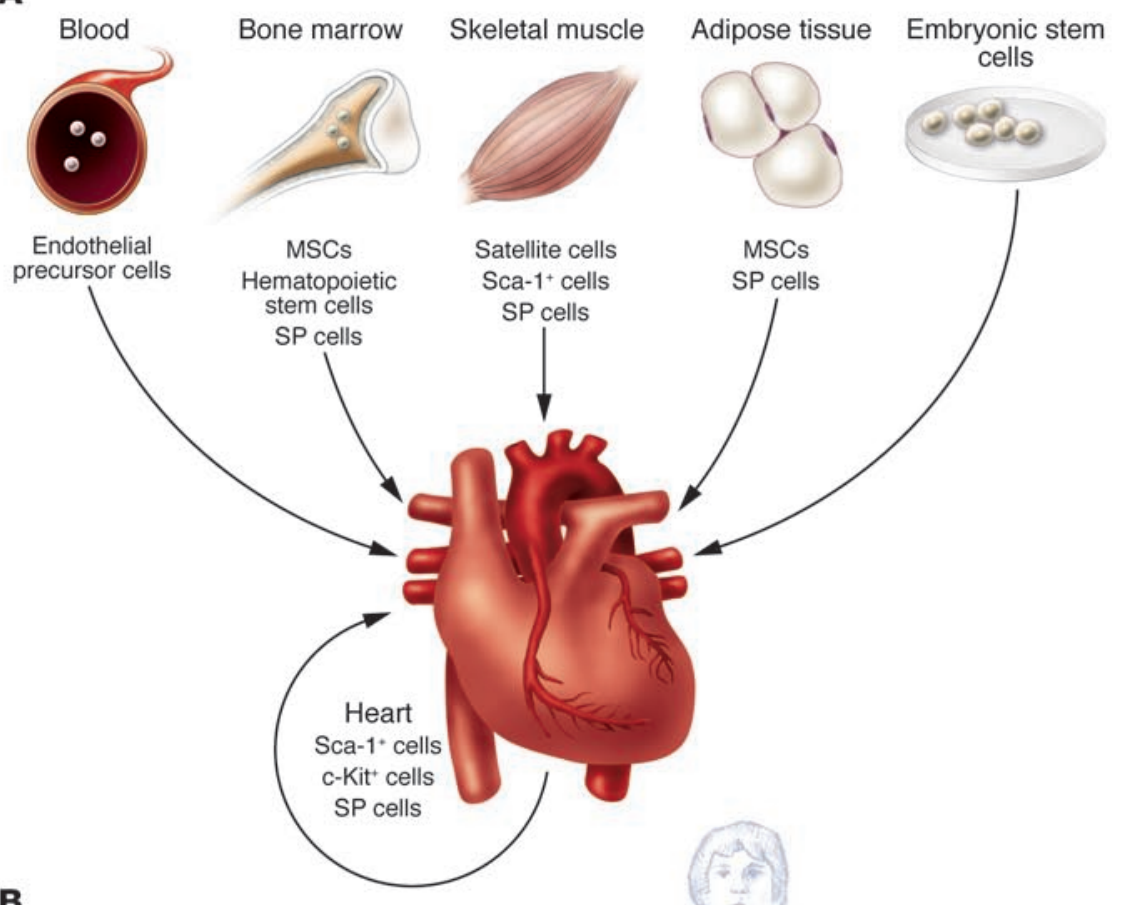

B
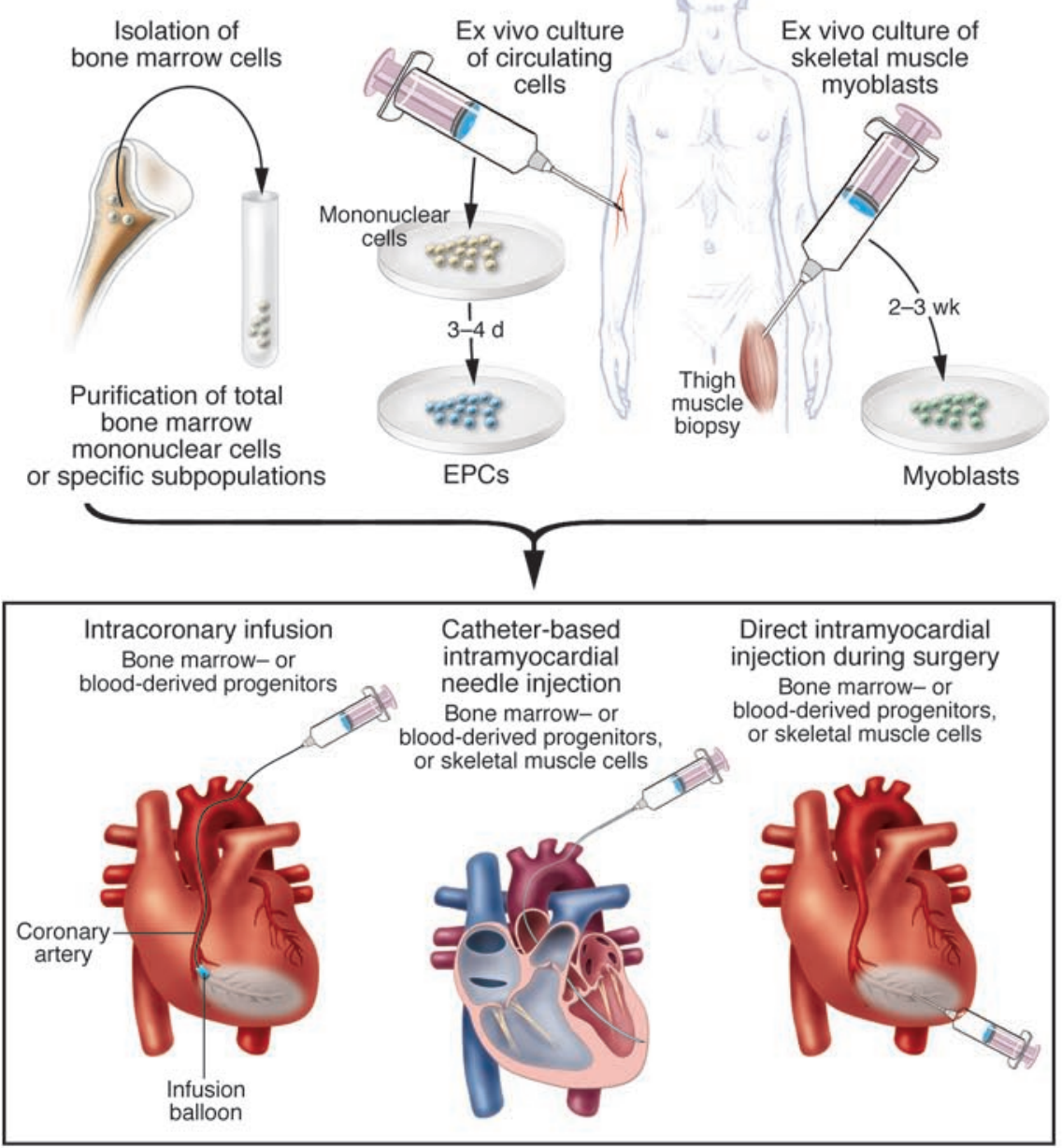

\section{Figure 1}

Sources of cells for cardiac repair, and routes of their administration. (A) Cells in current human trials include skeletal muscle myoblasts, unfractionated bone marrow, and circulating (endothelial) progenitor cells. Cells in preclinical studies include bone marrow MSCs, multipotent cells from other sources, and novel progenitor or stem cells discovered in the adult myocardium; see text for details. (B) Existing trials use intracoronary delivery routes (overthe-wire balloon catheters), intramuscular delivery via catheters (e.g., the NOGA system for electromechanical mapping), or direct injection during cardiac surgery. Not represented here are the theoretical potential for systemic delivery, suggested by the homing of some cell types to infarcted myocardium (39), and strategies to mobilize endogenous cells from other tissue sites to the heart.

lineages after single-cell grafting (28); mesenchymal stem cells or stromal cells (29); and multipotential adult progenitor cells (MAPCs), a subset of mesenchymal stem cells (MSCs) (30). Bone marrow is aspirated under local or general anesthesia, the entire mononuclear cell fraction is obtained (a heterogeneous mix of the above-mentioned cells), or specific subpopulations are purified, and isolated cells are injected into the heart without need of further ex vivo expansion. Expansion in cell culture could be desirable or essential, though, if defined but minute subpopulations prove to be advantageous (30).

Last, peripheral blood-derived progenitor cells are used both for clinical cardiac repair (13) and for neovascularization in peripheral arterial occlusive disease (7). These circulating cells (endothelial progenitor cells [EPCs]) are bone marrow derived (31), and, historically, therapeutic angiogenesis is the objective of virtually all clinical studies using bone marrow or its circulating derivatives for ischemic myocardium. For clinical use, EPCs are isolated from mononuclear blood cells and selected ex vivo by culturing in "endothelium-specific" medium for 3 days, prior to reinjection into the heart. The added hypothesis that such cells also might transdifferentiate to create new cardiomyocytes (32) is unrelated to the clinical studies' origin and dispensable to their rationale. Critiques of the clinical studies - where based on the absence or paucity of myocyte formation in mice (33-35) - raise useful questions as to the mechanisms for success (as measured to date by improvements in ventricular pump function), but overlook this most salient point, namely, the actual rationale. 


\section{Table 1}

Clinical trials of intracoronary progenitor cells for acute myocardial infarction

\begin{tabular}{|c|c|c|c|c|c|c|c|}
\hline Study & $N$ & $\begin{array}{l}\text { Days } \\
\text { after MI }\end{array}$ & Cell type & $\begin{array}{c}\text { Cell preparation } \\
\text { (volume/purification/culture) }\end{array}$ & $\begin{array}{l}\text { Mean cell } \\
\text { no. }\left(\times 10^{6}\right)\end{array}$ & Safety & $\begin{array}{l}\text { Myocardial } \\
\text { function }\end{array}$ \\
\hline $\begin{array}{l}\text { Strauer et al. } \\
\text { (12) }\end{array}$ & 10 & 8 & BMCs & 40 ml/Ficoll/overnight (Teflon) & 28 & + & $\begin{array}{l}\text { Regional contractility } \uparrow(\text { LVA); } \\
\text { endsystolic volume } \downarrow \text { (LVA); } \\
\text { perfusion } \uparrow \text { (scintigraphy) }\end{array}$ \\
\hline \multirow[t]{2}{*}{$\begin{array}{l}\text { TOPCARE-AMI } \\
(13,17,122)\end{array}$} & 59 & 4.9 & CPCs & $250 \mathrm{ml} / \mathrm{blood} / 3$ days & 16 & + & $\begin{array}{l}\text { Global contractility } \uparrow(\text { LVA/MRI); } \\
\text { end systolic volume } \downarrow(\text { LVA/MRI); } \\
\text { viability } \uparrow(\mathrm{MRI}) ;\end{array}$ \\
\hline & & & BMCs & $50 \mathrm{ml} /$ Ficoll/none & 213 & & $\begin{array}{l}\text { flow reserve } \uparrow \text { (Doppler); } \\
\text { similar results for both cell types }\end{array}$ \\
\hline BOOST (16) & $\begin{array}{l}30 \text { vs. } 30 \\
\text { randomized } \\
\text { controls }\end{array}$ & 4.8 & BMCs & $\begin{array}{l}150 \mathrm{ml} / \text { gelatin-polysuccinate } \\
\text { sedimentation/none }\end{array}$ & 2,460 & + & Global contractility $\uparrow(\mathrm{MRI})$ \\
\hline $\begin{array}{l}\text { Fernández-Avilés } \\
\text { et al. (123) }\end{array}$ & 20 & 13.5 & BMCs & 50 ml/Ficoll/overnight (Teflon) & 78 & + & $\begin{array}{l}\text { Global contractility } \uparrow(\mathrm{MRI}) \\
\text { end systolic volume } \downarrow \text { (MRI) }\end{array}$ \\
\hline
\end{tabular}

On the horizon of being tested for potential clinical application are other progenitor/stem cell populations: fat tissue-derived multipotent stem cells (36); multipotential cells from bone marrow or skeletal muscle (minuscule subpopulations, distinct from the unfractionated bone marrow and the myoblasts used in current trials) $(30,37)$; somatic stem cells from placental cord blood (38); and cardiac-resident progenitor cells that have a heightened predisposition to adopt the cardiac muscle fate (39-43). In each of these newer cases, techniques to isolate and purify the numerically minor population of potent cells will need to be optimized for clinical use, and enabling data from mammals larger than the mouse will surely be warranted.

\section{Routes of application}

Thus far, progenitor cells for cardiac repair have been delivered in 3 ways: via an intracoronary arterial route or by injection of the ventricular wall via a percutaneous endocardial or surgical epicardial approach (Figure 1). The advantage of intracoronary infusion - using standard balloon catheters - is that cells can travel directly into myocardial regions in which nutrient blood flow and oxygen supply are preserved, which hence ensures a favorable environment for cells' survival, a prerequisite for stable engraftment. Conversely, homing of intra-arterially applied progenitor cells requires migration out of the vessel into the surrounding tissue, so that unperfused regions of the myocardium are targeted far less efficiently, if at all. Moreover, whereas bone marrow-derived and blood-derived progenitor cells are known to extravasate and migrate to ischemic areas (44), skeletal myoblasts do not and furthermore may even obstruct the microcirculation after intra-arterial administration, leading to embolic myocardial damage.

By contrast, direct delivery of progenitor cells into scar tissue or areas of hibernating myocardium by catheter-based needle injection, direct injection during open-heart surgery, and minimally invasive thoracoscopic procedures are not limited by cell uptake from the circulation or by embolic risk. An offsetting consideration is the risk of ventricular perforation, which may limit the use of direct needle injection into freshly infarcted hearts. In addition, it is hard to envisage that progenitor cells injected into uni- formly necrotic tissue - lacking the syncytium of live muscle cells that may furnish instructive signals and lacking blood flow for the delivery of oxygen and nutrients - would receive the necessary cues and environment to engraft and differentiate. Most cells, if injected directly, simply die (45). For this reason, electromechanical mapping of viable but "hibernating" myocardium may be useful to pinpoint the preferred regions for injection (14). Finally, in diffuse diseases such as dilated nonischemic cardiomyopathy, focal deposits of directly injected cells might be poorly matched to the underlying anatomy and physiology.

Thus, it already appears likely that patients' individual pathobiology - the specific underpinnings of their heart failure - will ultimately influence, if not dictate, the source and route chosen among potential progenitor cell therapies. Given such variations in the underlying clinical context, it is not yet possible on the basis of existing pilot clinical trials, whose design and findings are detailed below, to assert an "optimal" cell type or "best" mode of delivery.

\section{Initial clinical results, 2000-2004}

Tables 1 and 2 summarize the results of all clinical trials studying cell-based myocardial repair published to date. It is vital to distinguish between those investigations performed on patients with acute myocardial infarction (Table 1) and those on patients with chronic heart failure due to prior myocardial infarction (Table 2), not only because of the different cell types and modes of delivery used, but also because fundamentally different pathophysiological processes are targeted. For example, in patients with acute myocardial infarction, progenitor cell transplantation is predicted to significantly modify postinfarction LV remodeling through enhanced neovascularization and reduced cardiomyocyte apoptosis, irrespective of long-term engraftment and transdifferentiation. Conversely, the former 2 mechanisms acting alone may have little or no benefit in patients with long-established scars, apart from the functional rescue of hibernating myocytes.

Given that myocardial ischemia acutely and potently upregulates the chemoattractants for neoangiogenesis (46), it was logical to test clinically an intracoronary infusion of bone marrow- or bloodderived progenitor cells in patients with acute myocardial infarc- 


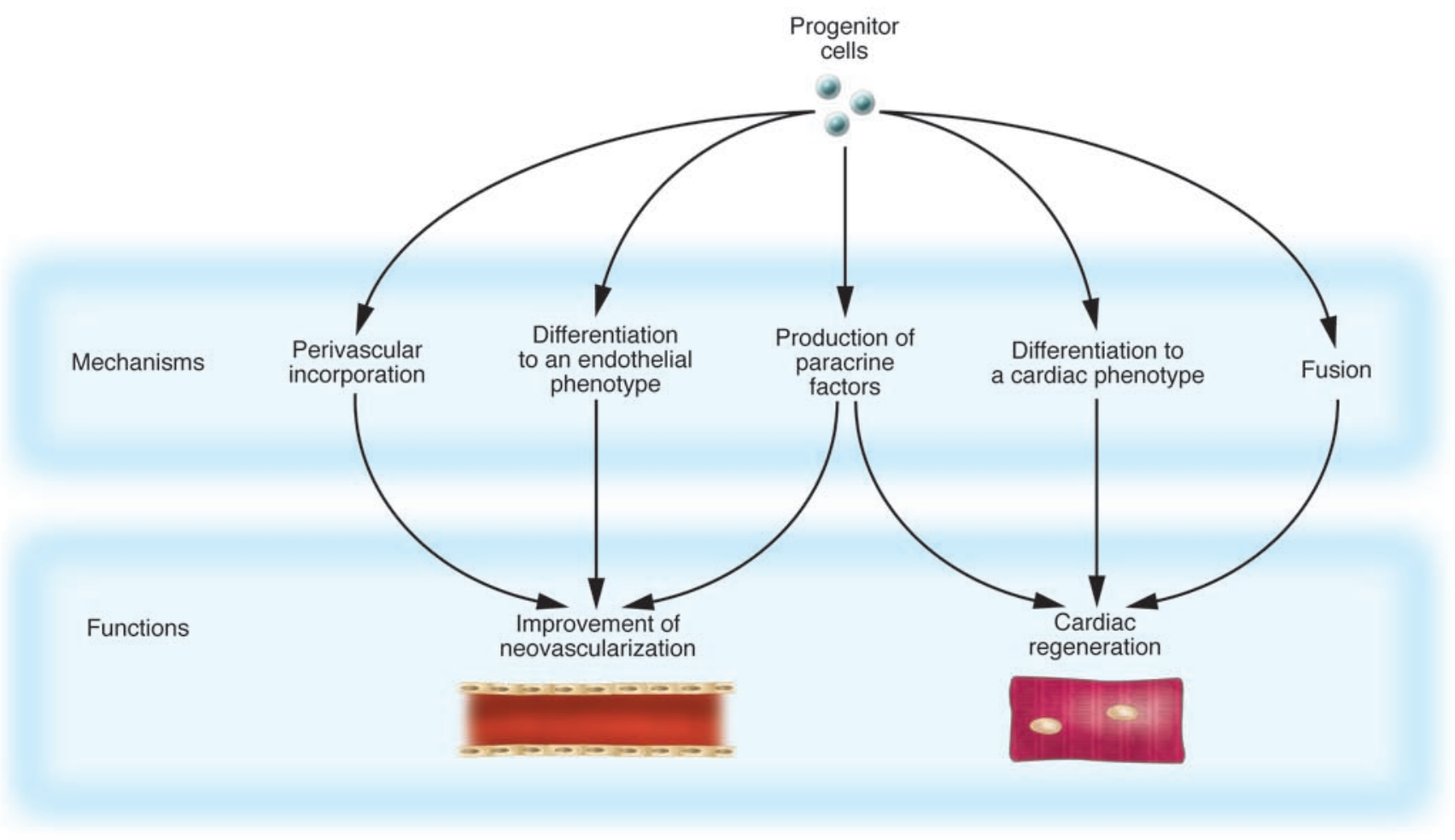

Figure 2

Mechanisms of action. Progenitor cells may improve functional recovery of infarcted or failing myocardium by various potential mechanisms, including direct or indirect improvement of neovascularization. Paracrine factors released by progenitor cells may inhibit cardiac apoptosis, affect remodeling, or enhance endogenous repair (e.g., by tissue-resident progenitor cells). Differentiation into cardiomyocytes may contribute to cardiac regeneration. The extent to which these different mechanisms are active may critically depend on the cell type and setting, such as acute or chronic injury.

tion (Table 1 and Figure 2). All the published trials reported nearly identical results - a 7-9\% improvement in global LV ejection fraction, significantly reduced end-systolic LV volumes, and improved perfusion in the infarcted area - 4-6 months after cell transplantation. Notably, in the only prospectively randomized trial so far (BOOST), global LV function was significantly improved in the cell-treated group compared with nontreated control subjects (16). Moreover, recent data from the TOPCARE-AMI trial, in which magnetic resonance was used as the optimal measure of LV function and mass, demonstrate that the improvement of LV function and absence of reactive hypertrophy are preserved even after 1 year, which suggests a sustained benefit on LV remodeling (17).

What technical variables might influence outcome? Surprisingly, none of the studies showed an association between cell numbers infused and extent of functional improvement over the ranges tested. Moreover, although the volumes of bone marrow harvested, the cell isolation procedures, and the number of cells infused varied considerably among trials, the reported improvements were nearly identical. Thus, it not yet possible to extract any critical elements of design that would maximize future studies' chance of success. Importantly, however, in all 4 trials - comprising a total of more than 100 patients who received intracoronary progenitor cell transplants - the observed complications did not exceed those expected in patients with acute myocardial infarction. Specifically, no arrhythmic complications resulted from delivery of bone marrow-derived progenitor cells, whether at surgery or by percutaneous approaches.
By comparison, in patients with chronic ischemic heart disease and old myocardial infarction, the initial attempts at cell-based myocardial repair were more heterogeneous in outcome, likely owing in part to the more heterogeneous populations treated (Table 2). The first such trial used skeletal muscle-derived progenitor cells, directly injected into the scarred region of the LV during open heart surgery for coronary artery bypass grafting (11). Global and regional LV function were significantly and persistently improved, although concomitant revascularization complicates the assessment of benefit. Indeed, in patients not undergoing simultaneous revascularization, transcatheter injection of myoblasts into the scar that had resulted from myocardial infarction 5-6 years earlier reduced the symptoms of heart failure, but without objective evidence of improved global LV function (15). Unfortunately, even though previous extensive animal experiments provided no hint of an arrhythmogenic risk $(21,23)$, the enthusiasm for injecting myoblasts into scar tissue for cardiac repair has been dampened by the fact that patients receiving this treatment have experienced life-threatening arrhythmias (47). Mechanistically, this phenomenon may relate to the lack of electrical coupling of skeletal muscle to neighboring cardiomyocytes (48) or, alternatively, be contingent on coupling by the few hybrid cells formed by fusion with adjacent cardiomyocytes, which generate spatially heterogeneous calcium transients (49). Therefore, currently, implantation of skeletal myoblasts requires the placement as well of an 
implantable cardioverter/defibrillator, as a mandatory adjunct to therapy (47). Importantly, in the 1 small, nonrandomized trial using bone marrow-derived progenitor cells for chronic ischemic heart failure, injection sites were chosen by electromechanical mapping of the LV endocardial surface to find areas of myocardial hibernation: significant increases in global LV ejection fraction resulted, with decreased end-systolic volumes and improved exercise capacity (14). While this functional improvement might be secondary to an improved blood supply to hibernating cardiomyocytes, it is also conceivable that an area of hibernating myocardium may provide a more favorable microenvironment for injected cells' survival and engraftment than a cell-depleted scar.

\section{Lessons from clinical pilot trials: more questions than answers}

Thus, patients in 3 disparate clinical scenarios - days, months, or years following infarction - have been subjected to cell transplantation for cardiac repair. In the case of acute myocardial infarction, the established safety and suggestive efficacy of intracoronary progenitor cell transplantation provide a cogent rationale for larger, randomized, double-blind trials and for expanding such studies from Europe to the United States. In the case of chronic ischemic heart failure, an additional question is whether identifying hibernating myocardium to direct cell therapy is essential to an effective outcome. It must also be shown whether delivery of skeletal myoblasts to established scar tissue late in the disease improves clinical outcome, once patients are protected against potential arrhythmias by an implantable defibrillator. Trials of each kind are currently ongoing and their results anticipated eagerly. Ultimately, it must be proven that cellular therapy aimed at cardiac repair not only improves pump function but also reduces mortality, morbidity, or both.

Beyond safety, beyond efficacy, what else do we need to know clinically? For ischemic disease, the technical armament is in hand for treating patients' hearts with progenitor cells but still at a very early stage - rudimentary experimental knowledge is being applied in the clinical arena, yet a variety of pivotal but straightforward utilitarian questions still remain unanswered (optimal patient selection, usefulness of repeated treatments). Nonischemic heart disease has yet to be addressed at all.

More complex and challenging is a series of pathobiological concerns, which have sent the scientific community from bedside to bench and back again. Certain patients' cells may be unsatisfactory, in their naive and unmanipulated state, which is now prompting systematic dissection of each step in progenitor cell function, from recruitment to plasticity. This task, in turn, is complicated by the fact that we do not yet understand the mechanisms underlying cellbased cardiac repair. For instance, the efficacy of skeletal muscle myoblasts (23) provided the impetus for human trials of skeletal muscle cells, but in the rabbit, diastolic functions are improved even by injected fibroblasts (50) and systolic performance improved to the same degree with bone marrow-derived cells as with skeletal muscle ones (51). Along with the issue of skeletal muscle cells' electrical isolation from host myocardium, this prompts the question of how mechanical improvements arise even in this ostensibly straightforward instance. Another reason to consider potential indirect mechanisms is that studies have called into question the extent to which bone marrow-derived cells implanted in the heart form cardiomyocytes (33-35). The majority of this review is, therefore, devoted to the biological horizons - namely mobilization, homing, neoangiogenesis, and cardiac differentiation (Figures 3 and 4) - and to evolving new insights that may enable cell therapy for cardiac repair to surpass the present state of the art.

\section{Cell mobilization}

The first hints that cytokine-induced mobilization may be a way to enhance cardiac repair came as an extrapolation of findings of results from efforts to increase EPC levels for neovascularization in another context - hind limb ischemia. Indeed, VEGF (52) and GM-CSF (53) were found to augment EPC levels and improve neovascularization, and subsequent studies documented EPC mobilization by numerous other proangiogenic growth factors - stromal cell-derived factor-1 (SDF-1), angiopoietin-1, placental growth factor, and erythropoietin (54-56). A wide array of interventions even more accessible clinically than growth factor administration enhance the number of circulating EPCs in adults, including treatment with HMG CoA reductase inhibitors (statins) and estrogens as well as exercise (57-59). Most studies confirmed an improvement in endothelial regeneration or neovascularization by mobilizing agents. However, such functional improvements may not rely entirely on EPC mobilization but may also - at least in part - be explained by direct proangiogenic or antiapoptotic effects. Hence, as discussed as a recurring theme in this review, the existence of known (and potential unknown) pleiotropic modes of action complicates the interpretation of regenerative therapies, even in cases where the beneficial effect is clear-cut and assured (Figure 3).

\section{Table 2}

Clinical trials of catheter-based progenitor cell delivery for chronic coronary heart disease

\begin{tabular}{|c|c|c|c|c|c|c|c|}
\hline Study & $N$ & $\begin{array}{l}\text { Delivery } \\
\text { technique }\end{array}$ & $\begin{array}{l}\text { Cell } \\
\text { type }\end{array}$ & $\begin{array}{c}\text { Cell preparation } \\
\text { (volume/purification/ } \\
\text { culture) }\end{array}$ & $\begin{array}{l}\text { Mean cell } \\
\text { no. }\left(\times 10^{6}\right)\end{array}$ & Safety & $\begin{array}{l}\text { Myocardial } \\
\text { function }\end{array}$ \\
\hline $\begin{array}{l}\text { Tse et al. } \\
(25)\end{array}$ & 8 & $\begin{array}{l}\text { Endocardial injection, guided } \\
\text { by electromechanical mapping }\end{array}$ & BMCs & 40 ml/Ficoll/none & Not reported & + & $\begin{array}{l}\text { Wall motion and thickening } \uparrow \text {; } \\
\text { hypoperfusion } \downarrow\end{array}$ \\
\hline $\begin{array}{l}\text { Fuchs et al. } \\
(124)\end{array}$ & 10 & $\begin{array}{l}\text { Endocardial injection, guided } \\
\text { by electromechanical mapping }\end{array}$ & BMCs & Filtered/none & 78.3 & + & $\begin{array}{l}\text { Angina score } \downarrow \text {; } \\
\text { stress-induced ischemia } \downarrow\end{array}$ \\
\hline $\begin{array}{l}\text { Perin et al. } \\
(14,18)\end{array}$ & 14 & $\begin{array}{l}\text { Endocardial injection, guided } \\
\text { by electromechanical mapping }\end{array}$ & BMCs & 50 ml/Ficoll/none & 30 & + & $\begin{array}{l}\text { Global contractility } \downarrow \text {; } \\
\text { endsystolic volumes } \downarrow \text {; } \\
\text { reversible perfusion defects } \downarrow \text {; } \\
\text { exercise capacity } \uparrow\end{array}$ \\
\hline
\end{tabular}




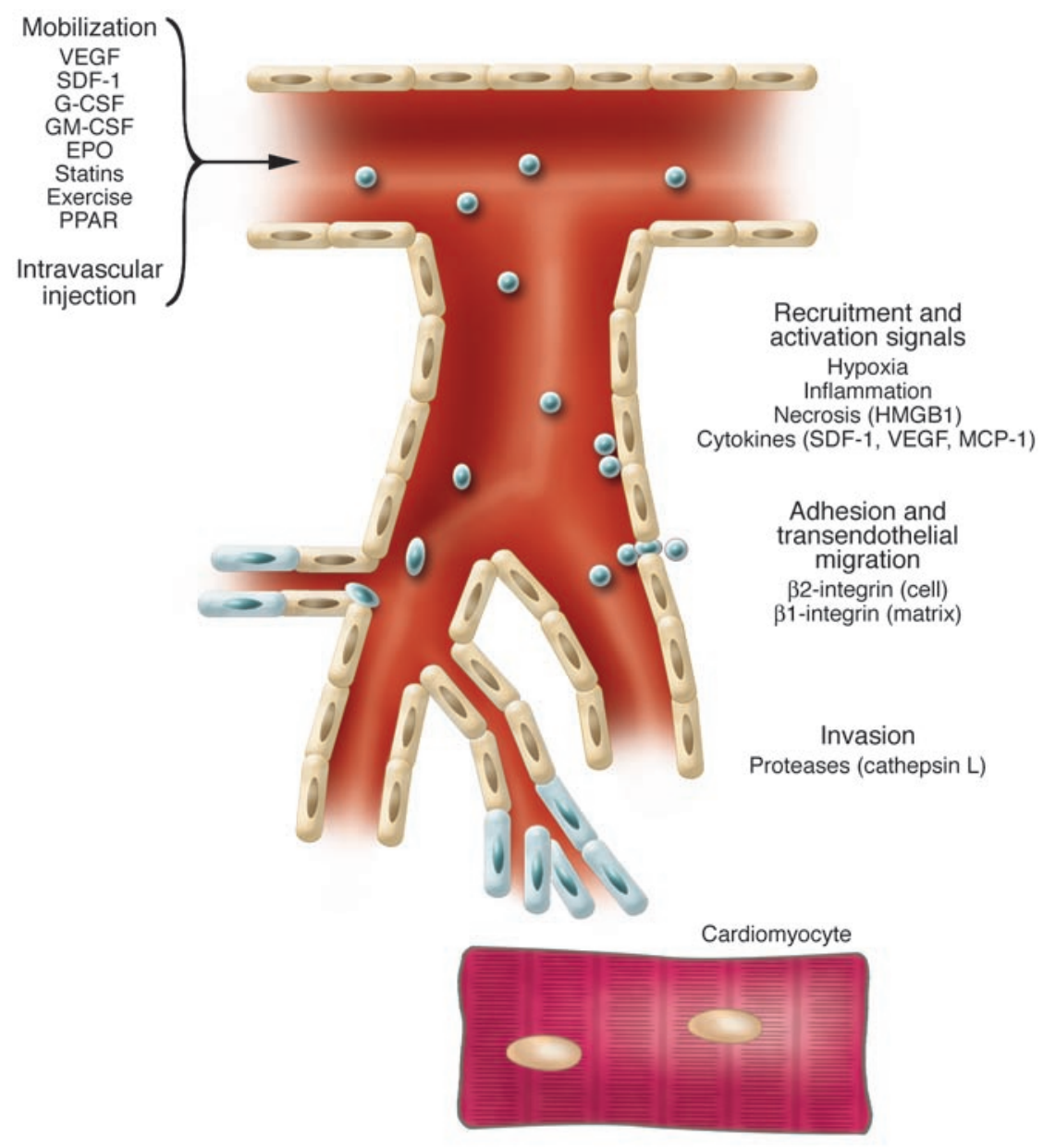

\section{Figure 3}

Mobilization and homing. After intravascular delivery or mobilization from bone marrow, progenitor cells are targeted to the sites of injury by multiple signals. Homing is mediated by a multistep process including the initial adhesion, transmigration, and invasion. Molecular mechanisms contributing to these individual steps are indicated but likely vary depending on the cell type and model. EPO, erythropoietin; MCP-1, monocyte chemoattractant protein-1.

tor cells were predominantly trapped by the spleen when given to athymic nude rats (44), and cardiac regeneration elicited by treatment with G-CSF plus SCF was documented only for animals lacking a spleen (60). The use of leukocyte-mobilizing cytokines might be most worthwhile combined with selective enhancements of progenitor cell homing or as a prelude to isolating cells for local delivery (63).

\section{Cell homing}

Defining the events in progenitor cell homing may enable better targeting of cells, most obviously when cells are mobilized from the bone marrow into the bloodstream. Later steps in homing, though, are instrumental to the impact even of progenitor cells infused locally into coronary arteries. Homing is a multistep cascade including the initial adhesion to activated endothelium or exposed matrix, transmigration through the endothelium, and, finally, migration and invasion of the target

A shift in emphasis from the heart's vessels to the heart itself was prompted by the report that bone marrow-derived cells can differentiate into cardiomyocytes when injected into injured myocardium and regenerate the heart effectively (32). Based on this discovery, hematopoietic stem cell-mobilizing factors - G-CSF and SCF (Kit ligand) - were used to improve cardiac regeneration experimentally (60), which quickly led to the initiation of clinical trials studying the ability of G-CSF to mobilize stem/progenitor cells in patients with coronary artery disease. This cytokine is used routinely in the treatment of humans, e.g., to help in harvesting cells for bone marrow transplantation. Although results from these first small trials do not permit any conclusion of efficacy, the safety of G-CSF in acute myocardial infarction has already come into question (61). The observed increase in restenosis may be partially explained by the study design (which precluded the standard clinical practice of promptly stenting the obstructed vessel), but the rise in leukocyte number to leukemic levels may be directly responsible, via plaque growth or destabilization. Adverse vascular events have also been attributed to G-CSF in patients with intractable angina who were not candidates for revascularization and even in patients without cardiac disease (62). In the future, it may be preferable to use strategies that augment circulating progenitor cells without causing massive inflammation.

A second open question regarding systemic mobilization is whether enough progenitor cells will home where needed, to the sites of cardiac injury (63). Systemically administered human progeni- tissue (Figure 3). The capacity to migrate and invade may be pivotal to functional integration even when cells are injected intramuscularly. Particularly in patients who lack the endogenous stimuli incited by acute ischemic injury, the enhancement of local homing signals or cells' ability to respond may be of critical importance.

While homing of hematopoietic progenitor cells to bone marrow has been studied extensively (64), the mechanisms for progenitor cells' homing to sites of tissue injury are only understood rudimentarily. SDF-1 appears to be one key factor that regulates trafficking of stem and progenitor cells to ischemic tissue (65), and local delivery of SDF-1 can enhance EPC recruitment and neovascularization $(63,66)$. Cell necrosis causes the release of a chromatin-binding protein, high mobility group box protein 1 (HMGB1), whose release acts as an extracellular "danger signal" and may stimulate progenitor cells' homing (67). Extracellular HMGB1 attracts mesoangioblasts in vitro and in vivo and likely plays a role in muscle regeneration (68). HMGB1 interacts with the receptor for advanced glycation end products, as well as Toll-like receptors 2 and 4 (69). The exact mechanisms that mediate cell attraction by HMGB1 are not yet clear and may involve additional receptors that are as yet unidentified.

Adhesion and transmigration of stem and progenitor cells are mediated by integrins. Indeed, integrin-dependent adhesion of EPCs is one effect of SDF-1 (70). Particularly, $\beta 2$ integrins were found to be essential for homing and improvement of neovascularization mediated by EPCs after hind limb ischemia (71). In a study 
of tumor angiogenesis focused on in vivo homing by embryonic EPCs from cord blood, the circulating cells arrested within tumor microvessels, extravasated into the interstitium, and incorporated into neovessels (72). The cells' initial physical arrest was suggested to be mediated by E- and P-selectin and P-selectin glycoprotein ligand-1 (72). However, this study was performed with embryonic endothelial progenitor cells in a tumor model of neovascularization - distinct from therapeutic angiogenesis in both respects. Many of the chemokines and adhesion molecules induced by cardiac ischemic injury are familiar players in other disorders (73), but different cell types may use different mechanisms for homing, and ischemia may differ from other attractants. Thus, a molecular dissection is essential to define the multiple steps of progenitor cell homing to and invasion of the myocardium, especially for those cells in current use for clinical cardiac repair and for other, novel, auspicious cells now in preclinical studies (39).

\section{Neoangiogenesis}

To date, there is no direct clinical evidence that cellular cardiomyogenesis in fact occurs in the human heart after transplantation of progenitor cells. Angiogenesis, improvements in scar tissue, and cytoprotection must be considered, along with transdifferentiation, as among the most important possible consequences of cellbased therapies for cardiac repair (Figure 3). Of these, most obviously, progenitor cells may improve neovascularization, which in turn would augment oxygen supply. Progenitor cells are expected to be of most benefit to cardiac regeneration or performance when used to treat jeopardized or hibernating cardiomyocytes. Neovascularization, in turn, can be mediated by the physical incorporation of progenitor cells into new capillaries $(74,75)$ or, in some settings, perivascular cells (76). Incorporated progenitor cells of most if not all types may release growth factors that promote angiogenesis by acting on mature endothelial cells (77). The extent to which progenitor cells contribute to vasculogenesis by becoming physical elements of newly formed vessels versus acting through secreted factors may plausibly depend on the circumstances of cell type and cardiac injury. However, human bone marrow-derived angioblasts exert both types of effect (78).

Cells engineered to overexpress angiogenic factors might enhance both their own survival and that of the recipient myocardium. As exemplified by the finding that myoblast-based delivery of VEGF led to an improved treatment outcome compared with direct viral gene transfer (79), cell therapy can be envisioned as a platform for secreted proteins' local production in the injured myocardium. More simply, hypoxic "preconditioning" enhances the ability of EPCs to rescue hind limb ischemia (80), conceivably through activation of the angiogenic gene program: in differentiating embryonic stem cells, formation of hemangioblasts (the common precursor of endothelial and hematopoietic progenitor cells) is activated by oxygen deprivation, requires hypoxia-inducible factor, and is regulated by VEGF plus other local signals (81).

\section{Cardiac myogenesis by noncardiac cells}

The possibility of cardiomyocyte formation by multipotent progenitor/stem cells first was raised by pioneering studies in which embryonic stem cells were grafted into mouse myocardium (82), the one cell type, along with germ cells, for which totipotency is assured. The formation of functional cardiomyocytes by mouse and human embryonic stem cells is proven according to many criteria $(83,84)$. Although religious, ethical, and political objections to using human embryonic stem cells have received justifiable attention (85), human embryonic stem cells, being allogeneic, also pose the clinical challenge of immunological barriers (86), which are obviated in all forms of autologous cell therapy.

At times equalling the intensity, if not the religious character, of the dispute over human embryonic stem cells is the debate regarding the extent - and even the existence - of the plasticity of progenitor cells (87-90). Challenging but appropriate concerns have been raised regarding the nature of proof. Is the appearance of multiple lineages due merely to a mixed assortment of starting cells? For which cell types, settings, and means of administration does fusion of donor and host cells create the appearance of transdifferentiation or multiple potentials? Is plasticity in propagated cells merely acquired in culture and not a reflection of native biology? The latter question is especially thorny, since cloning cells to homogeneity is a useful response to the concern that the starting population is mixed. Finally, developmental potential during normal maturation and in healthy adults may differ from plasticity after injury, and it is necessary therefore to test the latter explicitly. It simply makes the most sense to study cells' potential contributions to cardiac regeneration in settings, like infarction, where regeneration is most needed, rather than study plasticity just in normal hearts. The raging of this generic controversy about the plasticity of adult stem cells provides a partial explanation for the hostile climate in which claims of cardiac myogenesis by adult progenitor and stem cells have been received.

As proof of the concept that components of the heart can arise from a bone marrow source, myocardial ischemia/reperfusion injury was induced in mice following bone marrow reconstitution

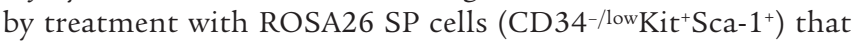
were genetically labeled to express $\beta$-gal ubiquitously (75). Donorderived myocytes were detected in the peri-infarct region, albeit at a prevalence of only $0.02 \%$; endothelial cells derived from bone marrow were seen far more frequently (3.3\%), as expected from the known origin of circulating EPCs. Recruitment of circulating bone marrow-derived cells to form cardiomyocytes also was shown in dystrophic mdx mice (91). In a particularly interesting study (32), female mice were subjected to permanent coronary artery occlusion, and viable myocardium bordering the infarction was injected with $\mathrm{Lin}^{-} \mathrm{Kit}^{+}$cells from the bone marrow of male transgenic mice widely expressing enhanced GFP (EGFP). These donor cells lack the surface markers of mature hematopoietic lineages but express the SCF receptor indicative of HSCs and some other primitive cell types. Extensive restorative growth was reported and donor origin shown by costaining for cardiac myosin plus the $\mathrm{Y}$ chromosome or green fluorescent protein. In addition, some $\mathrm{EPFP}^{+}$cells stained for an endothelial or smooth muscle marker and were, morphologically, organized into donor-derived vessels. Encouragingly, ventricular pump function was improved.

Subsequently, these results were challenged by researchers using seemingly identical conditions as well as complementary ones (33-35). In one example (34), the peri-infarct zone was injected with $\mathrm{Lin}^{-} \mathrm{Kit}^{+}$cells from bone marrow of transgenic mice bearing an $\alpha$-myosin heavy chain driven ( $\alpha$ MHC-driven; cardiomyocyte-specific) transgene encoding nuclear-localized $\beta$-gal. No nuclei stained blue, nor was regeneration seen by alternative criteria, e.g., ectopic staining for sarcomeric MHC in the area of necrosis. Other bone marrow-derived populations $\left(\mathrm{Lin}^{-} \mathrm{Kit}^{-} \mathrm{Sca}^{+}\right.$cells from the $\alpha M H C$ $n L a c Z$ mice; Lin-Kit ${ }^{+}$cells from $\alpha M H C$ - or $\beta A c t-E G F P$ mice) likewise failed to differentiate as donor cells (33-35). $\beta A c t-E G F P$ is expressed 
in the donor cells even when undifferentiated, and its use as a constitutive marker confirms that donor cells were successfully injected and retained in those studies where little or no cardiogenic differentiation was seen.

Supporting the hypothesis of progenitor cell plasticity, though, wild-type bone marrow cells from $\beta$ Act-EGFP donors give rise, rarely, to cardiac muscle fibers and, more often, to small, presumptively developing myocytes, when transplanted into the bone marrow of Sod1 mutant mice (92). Independent studies have shown that bone marrow-derived progenitor cells can be reprogrammed to express cardiac marker genes in vitro, including bone marrow stromal cells (93), EPCs grown together with cardiomyocytes (94), and bone marrow cells grown in the presence of ostensibly angiogenic factors (95). Hence, there is little room to doubt that bone marrow cells and their derivatives can acquire a cardiomyogenic phenotype, but the extent to which such differentiation occurs in vivo for the cell types in clinical use still needs to be better defined.

Apart from technical disparities in the end points, differences in the starting cells must be considered, too, as numerically minor components could be the responsible ones - e.g., MAPCs and SP cells. Determining the number of donor MSCs might be of particular value: these are relatively abundant in bone marrow, can express c-Kit, and have clearer potential than hematopoietic cells do to form cardiomyocytes upon injection into the heart (96-98). In a side-by-side comparison to define the subpopulations from which cardiomyocytes were formed (99), mice received bone marrow transplantation through the use of whole bone marrow, single long-term repopulating HSCs ("Tip"-SP Lin ${ }^{-} \mathrm{CD} 34^{-}{ }^{-}-\mathrm{Kit}^{+} \mathrm{Sca}-1^{+}$cells; ref. 28), or a clonal MSC line, all expressing EGFP. Recipient mice were subjected to coronary artery ligation, with or without G-CSF to help mobilize engrafted cells. Whole bone marrow generated dozens of EGFP $^{+} \alpha$-actinin ${ }^{+}$cells per heart, or thousands if G-CSF had been used. Although single HSCs effectively reconstituted the bone marrow and the peripheral blood nucleated cells, purified HSCs provided little or no contribution to bone marrow MSCs, mesenchymal lineages in culture, or cardiomyocytes after infarction. Conversely, bone marrow transplantation with MSCs yielded hundreds of $\mathrm{EGFP}^{+} \alpha$-actinin ${ }^{+}$cells. A plausible interpretation is that the MSCs in bone marrow - not HSCs - chiefly contribute to the creation of new cardiomyocytes following infarction. To date, human trials studying cardiac repair all have employed unfractionated bone marrow cells (presumably including bone marrow MSCs).

\section{Cardiac myogenesis by adult cardiac progenitor cells}

The quest for novel heart-forming cells in adult myocardium can be traced to several instigating rationales: the inability of skeletal myocytes to transdifferentiate; challenges to claims of bone marrow-derived cells' far-ranging plasticity; and an emerging countermodel of tissue-resident progenitor cells, sharing some signatures of "stemness" (100) yet predisposed to differentiate into lineages of the organ in which they reside.

In adults, the unique self-renewal potential of progenitor/stem cells - along with tumor cells and germ cells - is associated with telomerase reverse transcriptase (TERT), an RNA-dependent DNA polymerase that maintains the lariat-like loop (telomere) that caps chromosome ends (101). Telomerase expression and activity are markedly downregulated in the mouse heart soon after birth. A small number of cardiac cells express the surface marker stem cell antigen-1 (Sca-1), and this population, unlike Sca- - $^{-}$cells, contains telomerase at levels akin to those in newborn hearts (39). Cardiac- resident Sca- $1^{+}$cells lack the HSC markers CD45 and CD34 (also a marker of EPCs), lack hematopoietic transcription factors (Lmo2, Gata2, Tal), and thus are readily distinguished from bone marrow HSCs. Cardiac Sca- $1^{+}$cells also lack transcripts for cardiac structural genes but, intriguingly, express the majority of known cardiogenic transcription factors (Mef2c, Gata4, Srf, and Tead1/TEF-1, excepting a handful of others), congruent with the postulated properties of cardiac progenitor cells as undifferentiated yet predisposed to become cardiomyocytes.

In culture, cardiac Sca- $1^{+}$cells express $N k \times 2.5$, after which cardiac structural genes are activated, if treated with $5^{\prime}$-azacytidine to relax condensed chromatin (ref. 39; and see ref. 93). As evidence that differentiation was specific, and not a nondescript response to the DNA methylation inhibitor, inducing $\alpha M H C$ required the signal transduction pathway for bone morphogenetic proteins (BMPs), as differentiation was blocked by ex vivo deletion of the type IA $\mathrm{BMP}$ receptor (39). Adult cardiac Sca- $1^{+}$cells form beating cardiomyocytes with spontaneous calcium transients and may possess multipotency (41). However, multipotency needs to be proven in the progeny of single cells.

When given intravenously to mice just after ischemia-reperfusion injury, cardiac Sca- $1^{+}$cells home selectively to injured myocardium, interdigitate with surrounding host myocytes, and demonstrate robust differentiation in situ, constituting approximately $15 \%$ of the myocytes in the infarct "border zone" 2 weeks after grafting (39). Roughly $5 \%$ of donor-derived myocytes were still proliferating, as indicated by serine 10 phosphorylation of histone $\mathrm{H} 3$, a marker of Cdc2 activity. Given the possible existence of cell fusion as a confounding factor (102), a pair of genetic tags was utilized: $\alpha M H C-C r e$, the cardiomyocyte-specific expression of the DNA recombinase used widely for tissue-restricted knockout mutations, plus $R 26 R$, a ubiquitously transcribed but latent gene for $\beta$-gal (behind a Cre-deletable "stop" signal). $\alpha M H C$-Cre is inactive in cardiac Sca- $1^{+}$cells in their initial undifferentiated state. Hence, the induction of Cre protein fulfills 2 roles - as a marker of donor cell identity and of differentiation in situ. $\mathrm{Cre}^{+} \mathrm{LacZ}^{-}$cells are de novo differentiation products, whereas $\mathrm{Cre}^{+} \mathrm{LacZ}^{+}$ones denote differentiation associated with fusion (though not indicating which came first). The two modes of differentiation were equally prevalent. The extent of cell fusion in other models of cardiac repair must be determined empirically.

An intriguing subgroup within the Sca- $1^{+}$fraction consists of SP cells, discussed earlier in connection with bone marrow. SP cells have been found in other tissues, through use of the same flow cytometry test for dye efflux as is used for the SP cells in bone marrow itself. While many related transport proteins may provide a molecular marker for SP cells of the heart, Abcg2 seems to best serve this function in development and disease (42). Genes whose expression is enriched in cardiac SP cells include Ly6a (encoding Sca-1), genes for the cardiogenic transcription factors MEF2A and $\mathrm{MEF} 2 \mathrm{C}$, and genes suggesting that SP cells share an origin or developmental pathway with endothelial and hematopoietic cells.

Although cardiac Sca- $1^{+}$cells were typically negative for c-Kit (39, 41), this second marker also holds importance in heart. Prompted by the successful use of $\mathrm{Kit}^{+}$bone marrow cells in cardiac repair (32), cardiac-resident $\mathrm{Kit}^{+}$cells were sought (40): $\mathrm{Lin}^{-} \mathrm{c}-\mathrm{Kit}^{+}$cells were found in adult rat myocardium with a prevalence of approximately 1 per $10^{4}$ mature myocytes, frequently in clusters, with varying expression of cardiogenic transcription factors and rarer expression of cardiac-restricted sarcomeric proteins. As with car- 
diac Sca- $1^{+}$cells (39), cardiac c-Kit ${ }^{+}$cells lack CD45 and CD34 (40). Cardiac c-Kit ${ }^{+}$cells were self-renewing (propagated for months), clonogenic (expanded in culture after plating 1 cell per well), and multipotential (generating cardiomyocytes, smooth muscle cells, and endothelial cells) (40). When injected into the border of new infarcts, cardiac c-Kit ${ }^{+}$cells led to bands of regenerating myocardium in the region of necrosis, contributed to endothelium and vascular smooth muscle, and improved pump function and chamber geometry (40), much as the authors had reported using bone marrow c-Kit ${ }^{+}$cells (32). Results with clonally derived cardiac c-Kit ${ }^{+}$ cells were equivalent to those with the initial cardiac c-Kit ${ }^{+}$population, which suggests that an expandable source from within the heart might be applied to cardiac repair.

Where and how do cardiac progenitor or stem cells arise in the heart? Various models can be considered, ranging from persistence as undifferentiated remnants of heart-forming tissue in the early embryo, to a hematogenous origin (from bone marrow or even sites of earlier hematopoiesis, losing HSC markers in the process), to mechanisms involving ingrowth of the developing coronary vasculature. As an example of the first mechanism, postnatal cardioblasts numbering just a few hundred per heart have been identified on the basis of persistent expression of a LIM-homeodomain transcription factor, Isl1, especially in the atria, right ventricle, and outflow tract - regions where Isl1 is most prevalently expressed during cardiac organogenesis (43). By contrast, for cardiac Sca- $1^{+}$cells, the third potential mechanism may be favored, given the cells' striking similarities to the mesoangioblast, which include surface labeling, microarray findings, and earliest sites of marker expression $(39,103)$. How many cardiomyocytes, if any, are generated in the normal heart after birth by these new routes to heart muscle cell formation? What is the contribution of these pathways, unassisted, to cardiomyocyte formation in disease, as a reserve for the replacement of dead and dying cells? To answer these questions, the genetic strategy of fate mapping is likely relevant - indelibly tagging cells with an irreversible marker of their status - using, for example, a Sca-1driven gene for Cre recombinase plus a Cre-dependent reporter to permanently label the progeny of Sca- $1^{+}$cells, even once Sca- 1 is no longer expressed.

\section{Cell augmentation for cardiac repair}

The findings of unexpected persistence of cardiopoietic cells in adult hearts and effective cardiac repair by the noncardiac cells in current trials raise a number of fascinating questions. Although cell-based therapy has only taken its first steps into the clinic, limiting factors have already arisen as targets for future improvement. Ultimately, engineered cells may supercede naive cells.

First, how can one make delivered cells more durable, considering the adverse environment? Most stem cells share the property of stress resistance (100), but even stem cells die in the absence of blood flow. This concern is especially apt when progenitor cells are directly delivered into unperfused necrotic myocardium. Targeting injections to the margin of injury where oxygen supply persists is immediately workable (14), and biological means to augment the cells' survival are on the horizon, including the use of angiogenic factors, as discussed (79), or modification of MSCs with the antiapoptotic gene Akt (96).

Second, how can one restore progenitor cells to normal, where they are deficient in number or function? The functional capacity of bone marrow-derived cells is defective in patients with heart failure (104), and risk factors for atherosclerosis correlate inversely with the numbers and function of circulating EPCs (105, 106). Stem cell defects also occur as a consequence of aging (107, 108). Potential remedies include statins, which not only reduce risk factor load by lipid-lowering but also delay the onset of cellular senescence, telomere "uncapping," and DNA damage signals in human EPCs $(109,110)$. A Myb-like telomere-capping protein, telomere repeat-binding factor- 2 , is downregulated by cell stress cascades (4) and mediates the beneficial effect of statins on EPC function (110). Direct interference with telomere-based aging and death signals might also be achieved through the forcible expression of TERT $(4,111,112)$. Antioxidants or growth factors also might be used to promote telomerase activity $(108,113)$. TERT and other cell cycle activators may be useful in prolonging donor cell cycling either ex vivo or, especially if tightly controlled, following engraftment. Interestingly, the nuclear export of cyclin D1 and cyclin D3 limits these proteins' impact on cardiac regeneration when overexpressed in their wild-type form, whereas cyclin D2 is not excluded from the nucleus and led to marked infarct

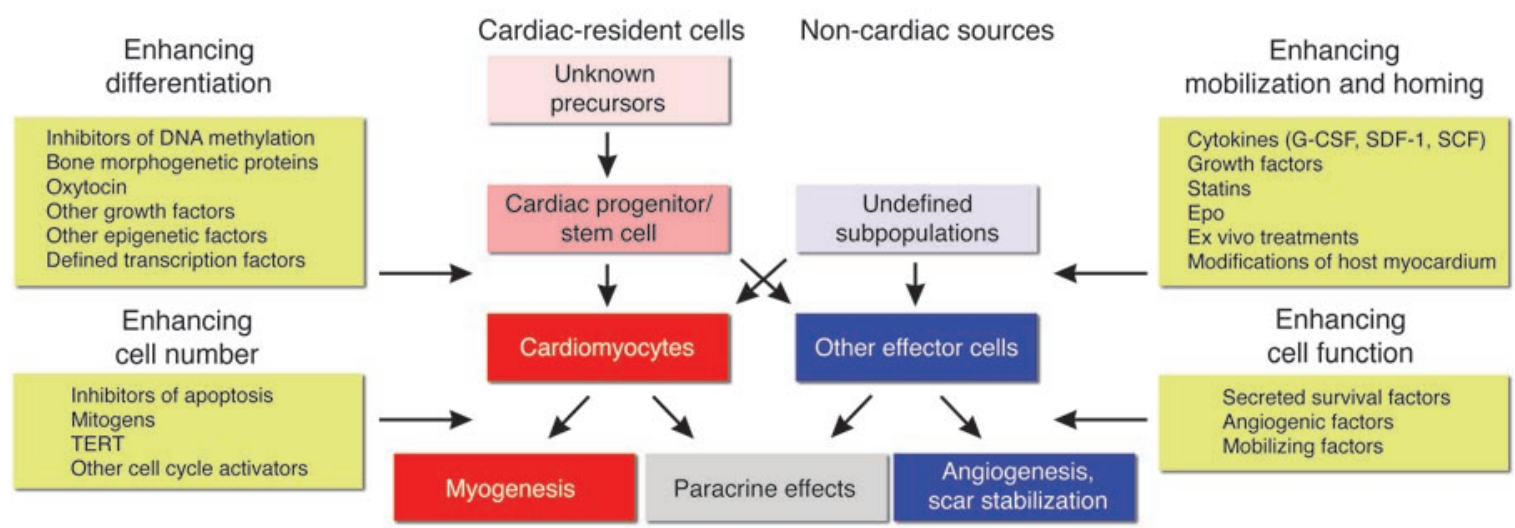

Figure 4

Current challenges for cell-based therapy in cardiac repair include identifying the origins of the novel cardiac progenitor and stem cells found within the heart, pinpointing the biologically active cells from bone marrow and other mixed populations, optimizing cell mobilization and homing, augmenting grafted cells' survival, defining the cues for cardiac differentiation, promoting donor cell proliferation ex vivo (or, if safe, in vivo), and exploiting cell therapy as a platform for secretory signals. 
regression (3). In this regard, it should prove instructive to understand better the molecular mechanisms that lock the cell cycle in terminally differentiated mammalian cardiomyocytes, including tumor suppressor proteins of the retinoblastoma family (114), and those that maintain a competence for cardiac proliferation in model organisms with enhanced capacity for cardiac repair (1, 2 ). The utility of zebrafish arises not only from the accessibility of its development outside the mother, but also (unlike chicks and frogs) from the fact that genome-wide mutagenesis is workable, while daunting, and several genes needed to drive heart repair have already been identified. These include Mps1, encoding a mitotic checkpoint kinase that is induced in the highly proliferative cells of the regeneration blastema (1). Blastemal regeneration, including that of the zebrafish heart, is also thought to entail the transient induction of Notch pathway components and Msx transcription factors $(115,116)$.

Third, what drives the cardiac fate in adult heart-forming cells? While some mechanisms for cardiac specification in injured adult hearts might differ from those in early embryos, better knowledge of the "wiring diagram" for commitment to the cardiac fate is expected to yield useful clues to enhance the differentiation process in susceptible cell types and even extend the range of donor cells that form heart muscle well $(8,117)$. Evidence for the importance of oxytocin in both early heart and adult cardiac Sca- $1^{+}$cells is a recent example $(41,118)$. Multiple autocrine or paracrine factors, from host myocardium or donor cells, provide essential instructions to enter the cardiac muscle lineage. Blocking TGF- $\beta$ or its relative, BMPs, prevents embryonic stem cells from becoming cardiomyocytes during coculture with ventricular muscle cells and following injection of the heart (119). Conversely, PDGF-AB enhances the induction of cardiac genes and beating cell aggregates in cultured bone marrow cells and increases the number of intra-scar cardiomyocyte islands when coinjected with bone marrow cells (95). As-yet-undefined local factors mediate the inductive effect of cardiomyocytes on cocultured EPCs (94) and is $11^{+}$ cardiac cells (43). Notably, azacytidine was key to activating the cardiomyocyte program in immortalized bone marrow stromal cells (93) and in cardiac Sca- $1^{+}$cells (39), and other epigenetic modifiers can be foreseen. High-throughput chemical and genetic screens will likely identify novel activators of cardiac myogenesis.

In summary, the existence of cardiac and noncardiac progenitor cells that are efficacious in cardiac repair next should stimulate vigorous inquiry into means to activate their migration, survival, growth, and differentiation (Figure 4). These are questions of great importance, whether one is envisioning the manipulation of cells ex vivo for subsequent administration or contemplating, instead, the activation of latent cells within the injured heart.

Finally, another approach to cardiac repair might be deemed "cell-free therapy. It remains formally unproven whether cardiac myogenesis is instrumental to improved cardiac function in the cell-based therapies discussed here, and other modes of action can be considered, beyond just angiogenesis, rescue of hibernating myocytes, and prevention of ventricular thinning. Potential paracrine actions of cell therapies might include immunomodulatory effects, as has been shown for mesenchymal stem cells (120), and other signals to modulate scar healing and remodeling. Additionally, paracrine mechanisms might suppress host cell death directly, both in acute infarction and in chronic heart failure, regardless of cause. A remarkable illustration of this principle is the discovery that thymosin $\beta 4$ - a secreted protein associated with the early heart on the one hand and with wound healing on the other - promotes cardiac cell migration, survival, and repair, working through the Akt survival pathway (121). Perhaps a primary role of cell therapy - at least for some modalities - is paracrine or chemoattractive. To what extent defined signals can bypass the need for cells in cardiac repair is unknown. At least for the moment, our cells likely know more than we do.

\section{Acknowledgments}

We thank K. Chien, J. Edelberg, L. Field, K. Fukuda, D. Losordo, B. Martin, and S. Rafii for suggestions. The authors are members of the Fondation Leducq Transatlantic Network of Excellence for Cardiac Regeneration. S. Dimmeler and A. Zeiher are supported by the Deutsche Forschungsemeinschaft and the EU European Vascular Genomics Network. M. Schneider is supported by the NIH, the Donald W. Reynolds Foundation, and the M.D. Anderson Foundation Professorship.

Address correspondence to: Stefanie Dimmeler, Molecular Cardiology, Department of Internal Medicine IV, University of Frankfurt, Theodor Stern-Kai 7, 60590 Frankfurt, Germany. Phone: 49-69-6301-6667; Fax: 49-69-6301-7113; E-mail: Dimmeler@ em.uni-frankfurt.de. Or to: Michael D. Schneider, Center for Cardiovascular Development, Baylor College of Medicine, One Baylor Plaza, Room 506D, Houston, Texas 77030, USA. Phone: (713) 7986683; Fax: (713) 798-7437; E-mail: michaels@bcm.tmc.edu.
1. Poss, K.D., Wilson, L.G., and Keating, M.T. 2002. Heart regeneration in zebrafish. Science. 298:2188-2190.

2. Bettencourt-Dias, M., Mittnacht, S., and Brockes, J.P. 2003. Heterogeneous proliferative potential in regenerative adult newt cardiomyocytes. J. Cell Sci. 116:4001-4009.

3. Pasumarthi, K.B., Nakajima, H., Nakajima, H.O., Soonpaa, M.H., and Field, L.J. 2005. Targeted expression of cyclin D2 results in cardiomyocyte DNA synthesis and infarct regression in transgenic mice. Circ. Res. 96:110-118.

4. Oh, H., et al. 2003. Telomere attrition and chk2 activation in human heart failure. Proc. Natl. Acad. Sci. U. S. A. 100:5378-5383.

5. Foo, R.S.-Y., Mani, K., and Kitsis, R.N. 2005. Death begets failure in the heart. J. Clin. Invest. 115:565-571. doi:10.1172/JCI200524569.

6. Losordo, D.W., and Dimmeler, S. 2004. Therapeutic angiogenesis and vasculogenesis for ischemic disease: part I: angiogenic cytokines. Circulation.
109:2487-2491.

7. Losordo, D.W., and Dimmeler, S. 2004. Therapeutic angiogenesis and vasculogenesis for ischemic disease: part II: cell-based therapies. Circulation. 109:2692-2697.

8. Olson, E.N., and Schneider, M.D. 2003. Sizing up the heart: development redux in disease. Genes Dev. 17:1937-1956.

9. Rosenthal, N. 2003. Prometheus's vulture and the stem-cell promise. N. Engl. J. Med. 349:267-274.

10. Mathur, A., and Martin, J.F. 2004. Stem cells and repair of the heart. Lancet. 364:183-192.

11. Menasché, P., et al. 2001. Myoblast transplantation for heart failure. Lancet. 357:279-280.

12. Strauer, B.E., et al. 2002. Repair of infarcted myocardium by autologous intracoronary mononuclear bone marrow cell transplantation in humans. Circulation. 106:1913-1918.

13. Assmus, B., et al. 2002. Transplantation of progenitor cells and regeneration enhancement in acute myocardial infarction (TOPCARE-AMI). Circula- tion. 106:3009-3017.

14. Perin, E.C., et al. 2003. Transendocardial, autologous bone marrow cell transplantation for severe, chronic ischemic heart failure. Circulation. 107:2294-2302.

15. Smits, P.C., et al. 2003. Catheter-based intramyocardial injection of autologous skeletal myoblasts as a primary treatment of ischemic heart failure: clinical experience with six-month follow-up. J. Am. Coll. Cardiol. 42:2063-2069.

16. Wollert, K.C., et al. 2004. Intracoronary autologous bone-marrow cell transfer after myocardial infarction: the BOOST randomised controlled clinical trial. Lancet. 364:141-148.

17. Schachinger, V., et al. 2004. Transplantation of progenitor cells and regeneration enhancement in acute myocardial infarction final one-year results of the TOPCARE-AMI trial. J. Am. Coll. Cardiol. 44:1690-1699.

18. Perin, E.C., et al. 2004. Improved exercise capacity and ischemia 6 and 12 months after transendocardial injection of autologous bone marrow 
mononuclear cells for ischemic cardiomyopathy. Circulation. 110:II213-II218.

19. Reinlib, L., and Field, L. 2000. Cell transplantation as future therapy for cardiovascular disease? A workshop of the national heart, lung, and blood institute. Circulation. 101:182-187.

20. Reinlib, L., and Abraham, W. 2003. Recovery from heart failure with circulatory assist: a working group of the national, heart, lung, and blood institute. J. Card. Fail. 9:459-463.

21. Koh, G.Y., Klug, M.G., Soonpaa, M.H., and Field, L.J. 1993. Differentiation and long-term survival of $\mathrm{c} 2 \mathrm{c} 12$ myoblast grafts in heart. J. Clin. Invest. 92:1548-1554.

22. Chiu, R.C., Zibaitis, A., and Kao, R.L. 1995. Cellular cardiomyoplasty: myocardial regeneration with satellite cell implantation. Ann. Thorac. Surg. 60:12-18.

23. Taylor, D.A., et al. 1998. Regenerating functional myocardium: improved performance after skeletal myoblast transplantation. Nat. Med. 4:929-933.

24. Hagege, A.A., et al. 2003. Viability and differentiation of autologous skeletal myoblast grafts in ischaemic cardiomyopathy. Lancet. 361:491-492.

25. Tse, H.F., et al. 2003. Angiogenesis in ischaemic myocardium by intramyocardial autologous bone marrow mononuclear cell implantation. Lancet. 361:47-49.

26. Goodell, M.A., Brose, K., Paradis, G., Conner, A.S., and Mulligan, R.C. 1996. Isolation and functional properties of murine hematopoietic stem cells that are replicating in vivo. J. Exp. Med. 183:1797-1806.

27. Goodell, M.A., et al. 1997. Dye efflux studies suggest that hematopoietic stem cells expressing low or undetectable levels of cd34 antigen exist in multiple species. Nat. Med. 3:1337-1345.

28. Matsuzaki, Y., Kinjo, K., Mulligan, R.C., and Okano, H. 2004. Unexpectedly efficient homing capacity of purified murine hematopoietic stem cells. Immunity. 20:87-93.

29. Pittenger, M.F., and Martin, B.J. 2004. Mesenchymal stem cells and their potential as cardiac therapeutics. Circ. Res. 95:9-20.

30. Jiang, Y., et al. 2002. Pluripotency of mesenchymal stem cells derived from adult marrow. Nature. 418:41-49.

31. Asahara, T., et al. 1999. Bone marrow origin of endothelial progenitor cells responsible for postnatal vasculogenesis in physiological and pathological neovascularization. Circ. Res. 85:221-228.

32. Orlic, D., et al. 2001. Bone marrow cells regenerate infarcted myocardium. Nature. 410:701-705.

33. Balsam, L.B., et al. 2004. Haematopoietic stem cells adopt mature haematopoietic fates in ischaemic myocardium. Nature. 428:668-673.

34. Murry, C.E., et al. 2004. Haematopoietic stem cells do not transdifferentiate into cardiac myocytes in myocardial infarcts. Nature. 428:664-668.

35. Nygren, J.M., et al. 2004. Bone marrow-derived hematopoietic cells generate cardiomyocytes at a low frequency through cell fusion, but not transdifferentiation. Nat. Med. 10:494-501.

36. Planat-Benard, V., et al. 2004. Spontaneous cardiomyocyte differentiation from adipose tissue stroma cells. Circ. Res. 94:223-229.

37. Jiang, Y., et al. 2002. Multipotent progenitor cells can be isolated from postnatal murine bone marrow, muscle, and brain. Exp. Hematol. 30:896-904.

38. Kogler, G., et al. 2004. A new human somatic stem cell from placental cord blood with intrinsic pluripotent differentiation potential. J. Exp. Med. 200:123-135

39. Oh, H., et al. 2003. Cardiac progenitor cells from adult myocardium: homing, differentiation, and fusion after infarction. Proc. Natl. Acad. Sci. U. S. A 100:12313-12318.

40. Beltrami, A.P., et al. 2003. Adult cardiac stem cells are multipotent and support myocardial regeneration. Cell. 114:763-776.
41. Matsuura, K., et al. 2004. Adult cardiac sca-1-positive cells differentiate into beating cardiomyocytes. J. Biol. Chem. 279:11384-11391.

42. Martin, C.M., et al. 2003. Persistent expression of the atp-cassette transporter, abcg2, identifies cardiac stem cells in the adult heart. In From stem cells to therapy. Keystone Symposia. Steamboat Springs, Colorado, USA. 75

43. Laugwitz, K.-L., et al. 2005. Post-natal isl1+ cardioblasts enter fully differentiated cardiomyocyte lineages. Nature. In press.

44. Aicher, A., et al. 2003. Assessment of the tissue distribution of transplanted human endothelial progenitor cells by radioactive labeling. Circulation. 107:2134-2139.

45. Beauchamp, J.R., Morgan, J.E., Pagel, C.N., and Partridge, T.A. 1999. Dynamics of myoblast transplantation reveal a discrete minority of precursors with stem cell-like properties as the myogenic source. J. Cell Biol. 144:1113-1122.

46. Lee, S.H., et al. 2000. Early expression of angiogenesis factors in acute myocardial ischemia and infarction. N. Engl. J. Med. 342:626-633.

47. Menasché, P., et al. 2003. Autologous skeletal myoblast transplantation for severe postinfarction left ventricular dysfunction. J. Am. Coll. Cardiol. 41:1078-1083.

48. Leobon, B., et al. 2003. Myoblasts transplanted into rat infarcted myocardium are functionally isolated from their host. Proc. Natl. Acad. Sci. U. S. A. 100:7808-7811.

49. Rubart, M., et al. 2003. Physiological coupling of donor and host cardiomyocytes after cellular transplantation. Circ. Res. 92:1217-1224.

50. Hutcheson, K.A., et al. 2000. Comparison of benefits on myocardial performance of cellular cardiomyoplasty with skeletal myoblasts and fibroblasts. Cell. Transplant. 9:359-368.

51. Thompson, R.B., et al. 2003. Comparison of intracardiac cell transplantation: autologous skeletal myoblasts versus bone marrow cells. Circulation. 108(Suppl. 1):II264-II271.

52. Asahara, T., et al. 1999. Vegf contributes to postnatal neovascularization by mobilizing bone marrow-derived endothelial progenitor cells. $E M B O J$. 18:3964-3972

53. Takahashi, T., et al. 1999. Ischemia- and cytokineinduced mobilization of bone marrow-derived endothelial progenitor cells for neovascularization. Nat. Med. 5:434-438.

54. Hattori, K., et al. 2001. Plasma elevation of stromal cell-derived factor- 1 induces mobilization of mature and immature hematopoietic progenitor and stem cells. Blood. 97:3354-3360.

55. Hattori, K., et al. 2002. Placental growth factor reconstitutes hematopoiesis by recruiting vegfr $1(+)$ stem cells from bone-marrow microenvironment. Nat. Med. 8:841-849.

56. Heeschen, C., et al. 2003. Erythropoietin is a potent physiologic stimulus for endothelial progenitor cell mobilization. Blood. 102:1340-1346.

57. Dimmeler, S., et al. 2001. HMG-CoA reductase inhibitors (statins) increase endothelial progenitor cells via the PI 3-kinase/Akt pathway. J. Clin. Invest. 108:391-397. doi:10.1172/JCI200113152.

58. Laufs, U., et al. 2004. Physical training increases endothelial progenitor cells, inhibits neointima formation, and enhances angiogenesis. Circulation. 109:220-226.

59. Iwakura, A., et al. 2003. Estrogen-mediated, endothelial nitric oxide synthase-dependent mobilization of bone marrow-derived endothelial progenitor cells contributes to reendothelialization after arterial injury. Circulation. 108:3115-3121.

60. Orlic, D., et al. 2001. Mobilized bone marrow cells repair the infarcted heart, improving function and survival. Proc. Natl. Acad. Sci. U. S. A. 98:10344-10349.

61. Kang, H.J., et al. 2004. Effects of intracoronary infusion of peripheral blood stem-cells mobilised with granulocyte-colony stimulating factor on left ventricular systolic function and restenosis after coronary stenting in myocardial infarction: the magic cell randomised clinical trial. Lancet. 363:751-756.

62. Matsubara, H. 2004. Risk to the coronary arteries of intracoronary stem cell infusion and g-csf cytokine therapy. Lancet. 363:746-747.

63. Askari, A.T., et al. 2003. Effect of stromal-cellderived factor 1 on stem-cell homing and tissue regeneration in ischaemic cardiomyopathy. Lancet. 362:697-703

64. Papayannopoulou, T. 2003. Bone marrow homing: the players, the playfield, and their evolving roles. Curr. Opin. Hematol. 10:214-219.

65. Ceradini, D.J., et al. 2004. Progenitor cell trafficking is regulated by hypoxic gradients through hif- 1 induction of sdf-1. Nat. Med. 10:858-864.

66. Yamaguchi, J., et al. 2003. Stromal cell-derived factor-1 effects on ex vivo expanded endothelial progenitor cell recruitment for ischemic neovascularization. Circulation. 107:1322-1328.

67. Scaffidi, P., Misteli, T., and Bianchi, M.E. 2002. Release of chromatin protein hmgb1 by necrotic cells triggers inflammation. Nature. 418:191-195.

68. Palumbo, R., et al. 2004. Extracellular hmgb1, a signal of tissue damage, induces mesoangioblast migration and proliferation. J. Cell Biol. 164:441-449.

69. Bianchi, M.E., and Manfredi, A. 2004. Chromatin and cell death. Biochim. Biophys. Acta. 1677:181-186.

70. De Falco, E., et al. 2004. Sdf-1 involvement in endothelial phenotype and ischemia-induced recruitment of bone marrow progenitor cells. Blood. 104:3472-3482.

71. Chavakis, E., et al. 2005. Role of b2-integrins for homing and neovascularization capacity of endothelial progenitor cells. J. Exp. Med. 201:63-72.

72. Vajkoczy, P., et al. 2003. Multistep nature of microvascular recruitment of ex vivo-expanded embryonic endothelial progenitor cells during tumor angiogenesis. J. Exp. Med. 197:1755-1765.

73. Dewald, O., et al. 2004. Of mice and dogs: speciesspecific differences in the inflammatory response following myocardial infarction. Am. J. Pathol. 164:665-677.

74. Urbich, C., and Dimmeler, S. 2004. Endothelial progenitor cells: characterization and role in vascular biology. Circ. Res. 95:343-353.

75. Jackson, K.A., et al. 2001. Regeneration of ischemic cardiac muscle and vascular endothelium by adult stem cells. J. Clin. Invest. 107:1395-1402.

76. De Palma, M., Venneri, M.A., Roca, C., and Naldini, L. 2003. Targeting exogenous genes to tumor angiogenesis by transplantation of genetically modified hematopoietic stem cells. Nat. Med. 9:789-795.

77. Fuchs, S., et al. 2001. Transendocardial delivery of autologous bone marrow enhances collateral perfusion and regional function in pigs with chronic experimental myocardial ischemia. J. Am. Coll. Cardiol. 37:1726-1732.

78. Kocher, A.A., et al. 2001. Neovascularization of ischemic myocardium by human bone-marrowderived angioblasts prevents cardiomyocyte apoptosis, reduces remodeling and improves cardiac function. Nat. Med. 7:430-436.

79. Askari, A., et al. 2004. Cellular, but not direct, adenoviral delivery of vascular endothelial growth factor results in improved left ventricular function and neovascularization in dilated ischemic cardiomyopathy. J. Am. Coll. Cardiol. 43:1908-1914.

80. Akita, T., et al. 2003. Hypoxic preconditioning augments efficacy of human endothelial progenitor cells for therapeutic neovascularization. Lab. Invest. 83:65-73.

81. Ramirez-Bergeron, D.L., et al. 2004. Hypoxia affects mesoderm and enhances hemangioblast specification during early development. Develop- 
ment. 131:4623-4634.

82. Klug, M.G., Soonpaa, M.H., Koh, G.Y., and Field, L.J. 1996. Genetically selected cardiomyocytes from differentiating embryonic stem cells form stable intracardiac grafts. J. Clin. Invest. 98:216-224.

83. Kehat, I., et al. 2001. Human embryonic stem cells can differentiate into myocytes with structural and functional properties of cardiomyocytes. J. Clin. Invest. 108:407-414. doi:10.1172/JCI200112131.

84. Xu, C., Police, S., Rao, N., and Carpenter, M.K. 2002. Characterization and enrichment of cardiomyocytes derived from human embryonic stem cells. Circ. Res. 91:501-508.

85. Blackburn, E. 2004. Bioethics and the political distortion of biomedical science. N. Engl. J. Med. 350:1379-1380.

86. Fairchild, P.J., Cartland, S., Nolan, K.F., and Waldmann, H. 2004. Embryonic stem cells and the challenge of transplantation tolerance. Trends Immunol. 25:465-470.

87. Anderson, D.J., Gage, F.H., and Weissman, I.L. 2001. Can stem cells cross lineage boundaries? Nat. Med. 7:393-395.

88. Verfaillie, C.M. 2002. Adult stem cells: assessing the case for pluripotency. Trends Cell Biol. 12:502-508.

89. Pomerantz, J., and Blau, H.M. 2004. Nuclear reprogramming: a key to stem cell function in regenerative medicine. Nat. Cell Biol. 6:810-816.

90. Wagers, A.J., Sherwood, R.I., Christensen, J.L., and Weissman, I.L. 2002. Little evidence for developmental plasticity of adult hematopoietic stem cells. Science. 297:2256-2259.

91. Bittner, R.E., et al. 1999. Recruitment of bone-marrow-derived cells by skeletal and cardiac muscle in adult dystrophic mdx mice. Anat. Embryol. 199:391-396.

92. Corti, S., et al. 2004. Wild-type bone marrow cells ameliorate the phenotype of sod1-g93a als mice and contribute to cns, heart and skeletal muscle tissues. Brain. 127:2518-2532.

93. Makino, S., et al. 1999. Cardiomyocytes can be generated from marrow stromal cells in vitro. J. Clin. Invest. 103:697-705.

94. Badorff, C., et al. 2003. Transdifferentiation of blood-derived human adult endothelial progenitor cells into functionally active cardiomyocytes. Circulation. 107:1024-1032.

95. Xaymardan, M., et al. 2004. Platelet-derived growth factor-ab promotes the generation of adult bone marrow-derived cardiac myocytes. Circ. Res. 94:E39-E45.

96. Mangi, A.A., et al. 2003. Mesenchymal stem cells modified with akt prevent remodeling and restore perfor- mance of infarcted hearts. Nat. Med. 9:1195-1201.

97. Toma, C., Pittenger, M.F., Cahill, K.S., Byrne, B.J., and Kessler, P.D. 2002. Human mesenchymal stem cells differentiate to a cardiomyocyte phenotype in the adult murine heart. Circulation. 105:93-98.

98. Saito, T., Kuang, J.Q., Lin, C.C., and Chiu, R.C. 2003. Transcoronary implantation of bone marrow stromal cells ameliorates cardiac function after myocardial infarction. J. Thorac. Cardiovasc. Surg. 126:114-123.

99. Kawada, H., et al. 2004. Nonhematopoietic mesenchymal stem cells can be mobilized and differentiate into cardiomyocytes after myocardial infarction. Blood. 104:3581-3587.

100.Ramalho-Santos, M., Yoon, S.J., Matsuzaki, Y., Mulligan, R.C., and Melton, D.A. 2002. "stemness": transcriptional profiling of embryonic and adult stem cells. Science. 298:597-600.

101. Harrington, L. 2004. Does the reservoir for self-renewal stem from the ends? Oncogene. 23:7283-7289.

102.Alvarez-Dolado, M., et al. 2003. Fusion of bonemarrow-derived cells with Purkinje neurons, cardiomyocytes and hepatocytes. Nature. 425:968-973.

103.Minasi, M.G., et al. 2002. The meso-angioblast: a multipotent, self-renewing cell that originates from the dorsal aorta and differentiates into most mesodermal tissues. Development. 129:2773-2783.

104. Heeschen, C., et al. 2004. Profoundly reduced neovascularization capacity of bone marrow mononuclear cells derived from patients with chronic ischemic heart disease. Circulation. 109:1615-1622.

105.Vasa, M., et al. 2001. Number and migratory activity of circulating endothelial progenitor cells inversely correlate with risk factors for coronary artery disease. Circ. Res. 89:E1-E7.

106.Hill, J.M., et al. 2003. Circulating endothelial progenitor cells, vascular function, and cardiovascular risk. N. Engl. J. Med. 348:593-600.

107. Edelberg, J.M., Tang, L., Hattori, K., Lyden, D., and Rafii, S. 2002. Young adult bone marrow-derived endothelial precursor cells restore aging-impaired cardiac angiogenic function. Circ. Res. 90:E89-E93.

108. Torella, D., et al. 2004. Cardiac stem cell and myocyte aging, heart failure, and insulin-like growth factor-1 overexpression. Circ. Res. 94:514-524.

109.Assmus, B., et al. 2003. Hmg-coa reductase inhibitors reduce senescence and increase proliferation of endothelial progenitor cells via regulation of cell cycle regulatory genes. Circ. Res. 92:1049-1055.

110.Spyridopoulos, I., et al. 2004. Statins enhance migratory capacity by upregulation of the telomere repeat-binding factor trf 2 in endothelial progenitor cells. Circulation. 110:3136-3142.
111. Murasawa, S., et al. 2002. Constitutive human telomerase reverse transcriptase expression enhances regenerative properties of endothelial progenitor cells. Circulation. 106:1133-1139.

112. Oh, H., et al. 2001. Telomerase reverse transcriptase promotes cardiac muscle cell proliferation, hypertrophy, and survival. Proc. Natl. Acad. Sci. U. S. A. 98:10308-10313.

113. Haendeler, J., et al. 2004. Antioxidants inhibit nuclear export of telomerase reverse transcriptase and delay replicative senescence of endothelial cells. Circ. Res. 94:768-775.

114. MacLellan, W.R., et al. 2005. Overlapping roles of pocket proteins in the myocardium are unmasked by germline deletion of $\mathrm{p} 130$ plus heart-specific deletion of rb. Mol. Cell. Biol. In press.

115. Raya, A., et al. 2003. Activation of notch signaling pathway precedes heart regeneration in zebrafish. Proc. Natl. Acad. Sci. U. S. A. 100(Suppl. 1):11889-11895.

116. Keating, M.T. 2004. Genetic approaches to disease and regeneration. Philos. Trans. R. Soc. Lond., B, Biol. Sci. 359:795-798.

117. Foley, A., and Mercola, M. 2004. Heart induction: embryology to cardiomyocyte regeneration. Trends Cardiovasc. Med. 14:121-125.

118.Jankowski, M., et al. 2004. Oxytocin in cardiac ontogeny. Proc. Natl. Acad. Sci. U. S. A. 101:13074-13079.

119. Behfar, A et al. 2002. Stem cell differentiation requires a paracrine pathway in the heart. FASEB J. 16:1558-1566.

120.Tse, W.T., Pendleton, J.D., Beyer, W.M., Egalka, M.C., and Guinan, E.C. 2003. Suppression of allogeneic T-cell proliferation by human marrow stromal cells: implications in transplantation. Transplantation. 75:389-397.

121. Bock-Marquette, I., et al. 2004. Thymosin b4 activates integrin-linked kinase and promotes cardiac cell migration, survival, and cardiac repair. Nature. 432:466-472.

122.Britten, M.B., et al. 2003. Infarct remodeling after intracoronary progenitor cell treatment in patients with acute myocardial infarction (TOPCARE-AMI): mechanistic insights from serial contrast-enhanced magnetic resonance imaging. Circulation. 108:2212-2218.

123.Fernandez-Aviles, F., et al. 2004. Experimental and clinical regenerative capability of human bone marrow cells after myocardial infarction. Circ. Res. 95:742-748.

124.Fuchs, S., et al. 2003. Catheter-based autologous bone marrow myocardial injection in no-option patients with advanced coronary artery disease: a feasibility study. J. Am. Coll. Cardiol. 41:1721-1724. 